\title{
ГАРАНТИИ И КОМПЕНСАЦИИ РАБОТНИКАМ ПРИ ЛИКВИДАЦИИ ПРЕДПРИЯТИЯ В 2020 ГОДУ
}

\section{GUARANTEES AND COMPENSATION TO EMPLOYEES IN CASE OF LIQUIDATION OF THE ENTERPRISE IN 2020}

E. Nikitin

Summary: Labor legislation guarantees employees dismissed in connection with the liquidation of the enterprise guarantees, compensation and payments. The employer, making a decision on the liquidation of the enterprise and the dismissal of employees on this basis, must fully comply with applicable law. Otherwise, the employee has an additional right: appeal to the court. As a result, the employer has new responsibilities, such as reinstatement, payment of nonpecuniary damage and involuntary absenteeism. The protection of the rights and interests of workers is at the forefront of the foundations of the constitutional system, as one of the basic principles of labor activity of subjects of labor relations. To minimize the risks associated with the liquidation of the enterprise for one reason or another, the employer must either independently fully examine the legal framework, or hire or hire an experienced lawyer. As a rule, the organization should have a hired worker with a legal education. Coverage in legal issues will allow to avoid unforeseen expenses, while protecting employees of their rights, and reduce the time for carrying out such a complex procedure. Courts, as a rule, when resolving a labor dispute take the side of the employee, respectively, if there are legal grounds for this. Liquidation of an enterprise cannot be attributed to force majeure, and it is not possible to relieve all of them of responsibility in case of violation of any legal norms. Thus, if the employer has not accepted and is not going to legally take a decision on the liquidation of the enterprise, then carrying out this procedure is at least not correct, inefficient and very expensive in the future.

Keywords: liquidation of an enterprise, legal norms, procedure, guarantees, compensation, certain categories of employees, dismissal, employer's obligation, reinstatement, administrative procedure, legal requirements, current legislation. рокатившийся по всему миру и сильно отразившийся на деятельности отечественного бизнеса вынужденный карантин, связанный с пандемией коронавируса, вынуждает громадное количество предпринимателей задуматься о ликвидации своих предприятия. В этой связи, исследование и анализ теории и практики соблюдения гарантий сотрудников работодателями при ликвидации предприятия в современных, по мнению экспертов, кризисных условиях заключает в себе актуальность темы исследования.

Изученность проблемы. Изучение рассматриваемой
Никитин Евгений Николаевич

аспирант, Институт Законодательной Инициативы и Сравнительного Правоведения при Правительстве РФ

(Москва)

nikitin@spbu.su

Аннотация: Трудовое законодательство гарантирует работникам, уволенным в связи с ликвидацией предприятия гарантии, компенсации и выплаты. Работодатель, принимая решение о ликвидации предприятия и увольнения работников на этом основании, должен в полной мере соблюдать действующее законодательство. В противном случае, у работника появляется дополнительное право: обращение с иском в суд. Как следствие у работодателя возникают новые обязанности, такие как восстановление на работе, выплачивание морального вреда и вынужденного прогула. Защита прав и интересов работников стоит на первом плане основ конституционного строя, как одни из основных принципов трудовой деятельности субъектов трудовых правоотношений. Для минимизации рисков, связанных с ликвидацией предприятия по тем или иным основаниям, работодатель должен либо самостоятельно в полной мере изучить законодательную базу, либо нанять или привлечь опытного юриста. Как правило, в штате организации должен быть наемный работник с юридическим образованием. Освещенность в правовых вопросах позволит избежать непредвиденных затрат, при защите работниками своих прав, и сократить время на проведение столь сложной процедуры. Суды, как правило, при разрешении трудового спора встают на сторону работника, соответственно, при наличии на то законных оснований. Отнести к форс-мажору ликвидацию предприятия нельзя, и снять со всех ответственность в случае нарушения каких-либо норм закона, не представляется возможным. Таким образом, если работодатель не принимал и не собирается принимать на законных основаниях решение о ликвидации предприятия, то проводить эту процедуру, как минимум, не корректно, неэффективно и в будущем очень затратно.

Ключевые слова: ликвидация предприятия, нормы права, процедура, гарантии, компенсации, отдельные категории работников, увольнение, обязанность работодателя, восстановление на работе, процедура административного производства, законные требования, действующее законодательство.

проблемы происходит на постоянной основе. Однако в полной мере изученной ее нельзя считать и связано это с тем, что в законодательство вносятся изменения, а экономическая политическая и иная обстановка постоянно требует возвращения к исследованию данного вопроса.

Целесообразность разработки темы. В связи с ожидаемыми ликвидациями компаний из-за коронавирусного кризиса 2020, Правительство России позаботилось о сотрудниках ликвидируемых организаций. Сразу два федеральных закона с 13 августа 2020 года внесли поправки в ТК РФ и Закон о госрегистрации юридических лиц и ин- 
дивидуальных предпринимателей.

Научная новизна работы заключается в том, в складывающихся условиях все большее количество предприятий будет ликвидировано. Это в принципе, новая ситуация для отечественной экономики и трудовых отношений. Подобная ситуация складывалась только в 1998 году, но с того времени существенно изменилось действующее законодательство. Сегодня с полной уверенностью можно утверждать, что текущая неординарная ситуация, связанная с вышеописанными событиями, требует такого же нестандартного и пристального внимания к тем проблемам, которые могут возникнуть у работника в процессе прекращения трудовых отношений в связи с ликвидацией предприятия.

Всё это также усугубляется еще и тем, что, во-первых, не все работники, чьи права нарушены, обращаются в судебные органы или органы прокуратуры для защиты своих прав, таким образом, придавая латентности такие правонарушения. Во-вторых, не все работники, чьи права нарушены работодателем, в должной мере это осознают. В-третьих, в нынешней ситуации, во многих секторах экономики ощущается безвыходная ситуация, в принципе, примером может служить туристская отрасль.

Цель исследования заключается в анализе прав и гарантий, и возможных ситуаций, приводящих к нарушению прав работников при прекращении трудового договора. В соответствии с целью к основным задачам можно отнести проведение анализа правового регулирования гарантии и компенсации работникам при расторжении трудового договора. А так же, рассмотрены отличительные черты. Выявлены проблемные вопросы соблюдения работодателями права работников

Теоретическая и практическая значимость. Возможность выявления определенных пробелов в трудовом законодательстве при применении норм, связанных с гарантиями и компенсациями работникам, помогает субъектам правоотношений осуществлять защиту нарушенных прав. В свою очередь это подводит к практическому применению данных законодательных норм, выводит на новый уровень зашиты и возможности заранее предусмотреть все возможные риски.

\section{Основная часть}

Российское законодательство интерпретирует понятие ликвидация предприятия следующим образом: юридический процесс, определенный законом по утрате гражданской правоспособности и как последствие, прекращение существования юридического лица.

Различие ликвидации от реорганизации заключается, собственно, в том, что статутные полномочия не пе- реходят новому юридическому лицу.

Общепризнанные нормы права, к которым возможно отнести порядок регулирования ликвидации предприятия предусматривают конкретный ряд гарантий и компенсаций сотрудникам.

В первую очередь Конституция РФ считается основателем правового регулирования трудовых правоотношений. В представленном случае специфичность конституционных общепризнанных норм заключается в том, что они не являются общепризнанными нормами прямого действия. Статья 37 Конституции РФ закрепляет основной момент, что государство гарантирует свободно распоряжаться своими способностями. Таким образом, регулирование каких-либо отношений осуществляется на принципах различных отраслей права.[1]

Данные гарантии зафиксированы в законе для защиты людей, оставшихся без работы и предоставления возможности получить средства к существованию до момента нового трудоустройства.

Российский изыскатель А.Я. Петров, отмечает, что применение общепризнанных норм трудового права в области гарантий и компенсаций сотрудникам, считается затруднительным в связи с неразработанной в должной мере нормативной базой.[2]

Процесс увольнения, предусмотренный для данной ситуации, имеет немного иной характер и более сложную процедуру, за нарушение которой предусмотрена ответственность в соответствии с действующим законодательством РФ.[3]

Статьи 81 и 180 Трудового кодекса РФ обязывает работодателя уведомить сотрудника в письменном виде под роспись за два месяца до предстоящего увольнения. Статья 296 Трудового кодекса РФ предусматривает срок в 7 календарных дней, но только для сезонных работников. Иной срок предусмотрен для сотрудников, которые заключили трудовой договор на срок менее двух месяцев. Согласно статье 292 Трудового кодекса РФ такие сотрудники уведомляются в письменном виде за три календарных дня.[4]

Законодательная возможность предусмотрена не случайно, что так же напрямую связано с гарантиями сотрудникам: возможность заранее найти себе новое место работы. Здесь, через правовую систему государство тем самым решает вопрос с безработицей и защитой прав трудящихся на всех этапах трудовой деятельности.

Бывают случаи, когда в период ликвидации предприятия сотрудник находится на больничном листе или в очередном оплачиваемом отпуске по графику. Тогда, ра- 
ботодатель обязан в силу закона уведомить сотрудника о предстоящем увольнении, направив ему уведомление заказным письмом с уведомлением. В таком случае срок, предусмотренный статьей 180 Трудового кодекса РФ, начинает исчисляться с момента получения сотрудником такого письма.[4] Однако, бывают случаи, когда работодатель ошибочно принимает за начало срока момент отправления уведомления, что является неверным. Зачастую неправильное истолкование и применение сроков уведомления и увольнения, ведет к обжалованию сотрудником действий работодателя в судебном порядке. Не исключается, что нарушение сроков носит под собой так же умышленный характер.

Дата и подпись сотрудника на уведомлении, является фактом, который подтверждает надлежащее уведомление о предстоящем расторжении трудового договора в связи с ликвидаций предприятия. Такая процедура является не формальной, а как раз таки общепризнанной и обязательной.

Статья 178 Трудового кодекса РФ регламентирует еще одну гарантию сотрудникам, которая заключается в выплате выходного пособия в размере среднего месячного заработка. При этом, это так же обязанность работодателя.[4]

Чтобы исключить возникновение конфликтных ситуаций между сотрудником и работодателем, следует сразу разграничить, что среднемесячный заработок, гарантированный сотруднику, может отличаться от размера заработной платы. К примеру, сотрудникам, занятым на сезонных работах, размер компенсации равен двухнедельному среднему заработку, а сотрудники, заключившие трудовой договор на срок менее двух месяцев и внешние совместители, компенсационные выплаты не получают.

Трудовое законодательство предусматривает выплаты сотрудникам в двух частях: выходное пособие и компенсация.

\section{Методология}

Методологической основой статьи в рамках проведения исследования стали принятые в отечественной юриспруденции общенаучные и специально-юридические методы: системный, формально-юридический и другие. При анализе доктрины, моделей правового регулирования и практики применения норм трудового права в современных отягощенных кризисными явлениями условиях использовался логико-правовой метод.

\section{Результаты}

Как правило, ликвидация предприятия, это неблаго- приятная экономическая ситуация. В связи с этим, работодателю необходимо прибегнуть к тому, чтобы обеспечить все права сотрудникам в соответствии с законом. На основании того, что ликвидация не связана с волей самого сотрудника, и не имеет под собой законных оснований как дисциплинарное взыскание для него, работодатель обязан соблюсти всю процедуру, не нарушив права всех «неподвластных». А как показывает судебная практика и процент удовлетворения судами исковых требований сотрудника, не все работодатели благонадежны и следуют конституционным принципам при осуществлении своей руководящей деятельности.

На этом же основании, отнести к форс-мажору ликвидацию предприятия нельзя, и снять со всех ответственность в случае нарушения каких-либо норм закона, не представляется возможным.

Требования, установленные действующим законодательством, в полной мере должны обеспечивать защиту нарушенных прав сотруднику, а работодатель, основываясь на общепризнанных принципах осуществления трудовой функции как руководителя, соблюдать эти права.

Равновесие между соблюдением и нарушением установлено быть не может. В связи с этим, необходимо усилить контроль за организациями и предприятиями, которые пришли к решению о ликвидации предприятия. Множество недочетов и пробелов, связанных с гарантиями и компенсациями сотрудников, можно проследить в трудовом законодательстве, которое не выделяет материальные и нематериальные гарантии. Что в свою очередь затрудняет правоприменительную практику.

Как было отмечено, законодатель предусмотрел выплаты сотрудникам в двух частях: выходное пособие и компенсация.

Для правильного толкования этих понятий, необходимости применения

и способе, определим, что является выходным пособием, а что компенсацией.

В день прекращения трудовых отношений работодатель производит окончательный расчет с сотрудником, что и является выходным пособием. У работодателя есть обязанность, предусмотренная Трудовым кодексом РФ выплачивать денежные средства на период до двух месяцев или до момента нового трудоустройства бывшего сотрудника в размере среднемесячного заработка, что является компенсацией.

На основании вышеизложенного, сотрудник получает три выплаты. Первая выплата осуществляется в период окончания трудовых отношений - выходное пособие, 
и две выплаты - в срок два месяца с момента увольнения сотрудника.[5]

Но, трудовое законодательство предусмотрело исключения, когда компенсационные выплаты с момента увольнения могут быть продлены до шести месяцев. Рассмотрим такие случаи. Человек, оставшийся без работы, имеет право встать на учет в центре занятости населения, при этом центром занятости населения может быть направлено бывшему работодателю решение о продлении положенных выплат. Однако, такое решение может быть направлено в случае, если человек в течение двух месяцев не трудоустроился на новое место работы, что регламентировано статьей 178 Трудового кодекса РФ.[4] В случае фиксации нарушения учета на бирже труда, решение о продлении выплат не выдается. Это связано с невозможность злоупотребления работниками своими законными правами.

Статья 127 Трудового кодекса РФ содержит право всех сотрудников на получение компенсации за дни неиспользованного отпуска.[4] В соответствии со статьей 115 Трудового кодекса РФ продолжительность отпуска составляет 28 календарных дней.[4] Это без учета разного рода дополнительных отпусков, которые могут быть положены сотруднику. Такая компенсация рассчитывается пропорционально отработанному промежутку времени у данного работодателя, до момента ликвидации предприятия в соответствии с Правилами об очередных отпусках по НКТ СССР от 1930 года №169 и нормами об отпусках Трудового кодекса РФ.[6]

Так же, в коллективном договоре предприятия или Положении об оплате труда могут быть отражены и прочие выплаты сотруднику в случае ликвидации. В прочем это зависит от решения, принятого работодателем и профсоюзной организацией. Такой же точки зрения придерживается В.И. Миронов. [7, с. 257]

Действующим законодательством предусмотрены положения о гарантиях отдельным категориям сотрудников. Рассмотрим правовые позиции в разрезе трудового законодательства.

Одной из категорий, являются сотрудники, уволенные с работы в связи с ликвидацией предприятия, находящиеся в условиях Крайнего Севера. Такие сотрудники, так же имеют возможность после расторжения трудового договора встать на учет в центре занятости населения, только с одним отличием: в течении двух месяцев, а не двух недель, как положено для «обычных» бывших сотрудников. Так же, еще одной отличительной чертой и положительным моментом, отраженным в статье 318 Трудового кодекса РФ, является выплата компенсации в течение трех месяцев с момента увольнения.[4] Вопрос о продлеии таких выплат решается центром занятости на общих основаниях.

Еще одна уязвимая категория сотрудников, женщины, находящиеся в отпуске по уходу за ребенком и беременные женщины и по беременности и родам. Несмотря на то, что трудовое законодательство полностью защищает таких сотрудников от увольнения, ликвидация предприятия в таком случае является исключением. Что содержится в статье 261 Трудового кодекса РФ.[4] Процесс увольнения происходит на общих основаниях: начиная от уведомления и заканчивая выплатами и компенсациями.

Законодательство РФ закрепило следующие выплаты: по беременности и родам; при рождении ребенка; за постановку на учет на ранних сроках беременности; по уходу за детьми до полутора и до трех лет; материнский капитал. Постановлением правительства №652 введено дополнительное пособие - ежемесячная выплата на ребенка до 1,5 лет. Все же, положение женщин в данном случае немного привилегированнее по сравнению с остальными категориями сотрудников.

Пенсионеры так же подпадают под особую категорию сотрудников при ликвидации организации. Пенсионеры имеют все те же права и гарантии при ликвидации, что и «обычные» работники. Но, при рассмотрении трудовых споров, эти правила не распространяются на граждан, которым на момент ликвидации уже выплачивается пенсия. В обоснование своих выводов суды указывают, что отраженные в данной статье выплаты уже являются мерами социальной поддержки безработных, и это зафиксировано в действующем законодательстве.

Возможно, могут возникнуть споры в этом вопросе, но бухгалтера можно отнести к особой категории сотрудников при ликвидации предприятия. Данная позиция основана на следующих основаниях. До окончания действия трудового договора в связи с ликвидацией предприятия бухгалтерия должна произвести полный расчет со всеми работниками, своевременно. Процесс увольнения работников может так же быть в момент закрытия баланса или сдачи окончательного отчета. Соответственно, должны быть подписаны соответствующие документы главным бухгалтером. Таким образом, все права по подписанию переходят либо генеральному директору, либо учредителю организации, в зависимости от того, что отражено в учредительных документах. При этом, все размеры и виды компенсации и выплат, которые предусмотрены для главного бухгалтера такие же, которые предусмотрены для основных категорий сотрудников.

Некоторые работодатели после принятия решения о ликвидации предприятия могут прибегнуть к определенным уловкам, которые сотруднику на первый взгляд 
могут показаться незначительными.

Работнику может поступить предложение о расторжение трудового договора по инициативе сотрудника или по соглашению сторон. При этом, законодательно не подкованный сотрудник может с легкостью согласиться на такую, можно сказать, не хитрую махинацию. Такое положение выгодно работодателю тем, что он может сократить расходы на выплаты при увольнении, так как размер и количество компенсаций при ликвидации предприятия намного отличается от вышеперечисленных вариантов увольнения.

В таких случаях закон на стороне работника, а не работодателя и он вправе ответить отказом на такого рода предложения, а в случае угроз либо давления, либо нарушении каких-либо других прав на выплаты, например- невыплата денежной компенсации, имеет право обратится в суд, органы прокуратуры или трудовую инспекцию.

При подаче жалобы в трудовую инспекцию, в отношении работодателя будет инициирована проверка, и процедура административного производства, в случае выявления нарушения (абз. 7 ч. 7 ст. 360 ТК РФ).

Органы прокуратуры, при поступлении жалобы о нарушении права при ликвидации предприятия проводит прокурорскую проверку с выдачей акта прокурорского реагирования. Так же, может быть инициирован иск о защите нарушенных прав в суд (абз. 7 ч. 7 ст. 360 ТК РФ).

В случае невыплаты компенсации и обращения в суд с иском и вынесении решении об удовлетворении такого иска, работодатель обязан произвести полный расчет в установленном порядке, а также возместить моральный вред, заявленный истцом. В случае неисполнения работодателем решения суда в добровольном порядке может быть подан исполнительный лист для принудительного взыскания задолженности (ст.392 ТК РФ).

Если ликвидация организации не состоялась, но сотрудники уже уволены, то на основании решения суда они могут быть восстановлены на прежнее место работы. Но, для работодателя это не совсем благоприятная ситуация в финансовом плане. Таким образом, принимать решение о ликвидации предприятия необходимо на законных основаниях, так как существует много неблагоприятных последствий для работодателя.

При вынесении решения судом о восстановлении сотрудника на работе, в связи с тем, что ликвидация признана незаконной, у работодателя возникает множество вопросов, одним из которых как вернуть все ранее выплаченные пособия и компенсации.
Трудовым кодексом РФ возврат выплат сотрудником в таком случае не урегулирован. Исходя из анализа норм и принимая во внимание логические соображения, если сотрудник восстановлен в должности в связи с незаконным увольнением, то все выплаченные суммы являются неосновательным обогащением.

Статья 234, статья 394 Трудового кодекса РФ обязывает работодателя, в случае признания увольнения незаконным, выплатить средний заработок за все время вынужденного прогула.[4] Одним из вариантов, которым может воспользоваться работодатель, это зачет выплаты среднего заработка в счет возвращения выплат при увольнении. Но, могут возникнуть случаи, когда сотрудник получил при увольнении сумму больше, чем работодатель должен выплатить сейчас. В таком случае, работодатель может прибегнуть к обращению с иском в суд о возврате разницы, либо просто при первой выплате заработной плате произвести удержание.

Однако, статья 1109 Гражданского кодекса РФ указывает на невозможность взыскания выходного пособия в качестве неосновательного обогащения.[9] Данная норма основывается на том, что в случае отсутствия недобросовестности со стороны сотрудника и счетной ошибки данные выплаты взыскать не представляется возможным. Поэтому, в случае подачи работодателем такого иска, его ждет решение суда об отказе в удовлетворении со ссылкой на то, что взыскание этих сумм с восстановленного на работе сотрудника законодательством не предусмотрено, и как следствие, потраченное время в пустую.

Так же, статья 137 Трудового кодекса РФ содержит закрытый перечень оснований для удержаний из зарплаты, а положения Гражданского кодекса РФ о зачете не распространяются на трудовые отношения.

По таким же основаниям, вернуть работодателю денежные средства, выплаченные за неиспользованный отпуск, так же не получится.

Таким образом, удержание таких выплат из работной платы не носит под собой законных оснований. Соответственно в случае, если работодатель удержит из заработной платы, выплаченные при увольнении суммы, то сотрудник имеет право обратиться в суд, и взыскать эту суму обратно, а также имеет право получить соответствующую компенсацию.[10] Практика удовлетворения судом таких категорий исков велика. В случае, если сотрудник воспользуется правом обращения в трудовую инспекцию за восстановлением нарушенных прав, это повлечет за собой привлечение работодателя к административной ответственности по статье ст. 5.27 Кодекса об административных правонарушениях РФ.[11] 
Единственным эффективным вариантом, которым может воспользоваться работодатель, это зачет выходного пособия в счет среднего заработка за вынужденный прогул, согласно п. 62 постановления Пленума Верховного Суда РФ от 17.03.2004 N 2 «О применении судами Российской Федерации Трудового кодекса РФ».[12]

Еще при рассмотрении дела о восстановлении сотрудника работодатель может заявить о том, что в случае признания увольнения незаконным, суд должен зачесть сумму компенсации за неиспользованный отпуск.[13] Если суд в этом откажет, у работодателя еще будет возможность удержать спорную сумму из отпускных при предоставлении сотруднику ежегодного оплачиваемого отпуска.

В письме федеральной службы по труду и занятости от 14 июня 2012 г. № 853-6-1 «О предоставлении отпуска работнику при восстановлении на работе» сказано, что компенсацию за неиспользованный отпуск, выплаченный восстановленному работнику, можно зачесть при расчете оплаты при предоставлении очередного отпуска.[14] При этом, работодатель имеет возможность при рассмотрении дела о восстановлении сотрудника ходатайствовать, о том, что в случае, если судом будет признано увольнение сотрудника незаконным, зачесть сумму компенсации за неиспользованный отпуск.

\section{Выводы}

Зачастую, «эффективные» работодатели, в процессе ликвидации активно прибегают к разнообразным действиям, которые направлены на минимизацию их расходов. В частности, сотрудникам предлагается расторгнуть трудовой договор по соглашению сторон либо по собственному желанию.

Итогом такого не обдуманного действия со стороны работника, в случае принятия им предложений от «эффективного» работодателя становиться фактически отказ от полагающихся при ликвидации предприятия выплат и компенсаций. Поскольку порядок компенсаций при увольнении по другим основаниям отличается от ликвидационного.

В этой связи, следует зафиксировать, что сотрудник вправе не соглашаться на предложение работодателя. Одновременно следует отметить, что работник, который не имел дисциплинарных взысканий и наказаний за трудовые проступки и который добросовестно выполнял свои обязанности, в полной мере может рассчитывать на полный объем компенсаций и выходного пособия.

Поправки в законодательные акты, внесенные Законом от 13.07.2020 № 210-Ф3 и Законом от 13.07.2020 № 203-Ф3 не позволят работодателю ликвидироваться раньше, пока он полностью не рассчитается со своими уволенными в связи с ликвидацией сотрудниками.

При этом за нанимателем сохранено право при увольнении работников выплатить им всё, что положено за период трудоустройства, сразу. То есть, не дожидаясь истечения временных сроков, после которых надо платить следующее выходное пособие.

По закону, если уволенный в процессе ликвидации работник не трудоустроится в ближайшее после увольнения время, он может обращаться к бывшему работодателю за выплатой среднего заработка. Срок - не позднее 15 рабочих дней после окончания:

второго месяца поиска работы (пособие на первый месяц должно быть выплачено в день увольнения);

третьего месяца со дня увольнения - если служба занятости решит продлить выплату среднего заработка.

На перечисление средств у работодателя есть 15 календарных дней после того, как сотрудник обратился с требованием. Если работник трудоустроится до конца второго или третьего месяца, бывший наниматель должен оплатить средний заработок за дни, когда работник еще искал новую работу.

До появления указанных новых законов 2020 оставался спорный момент: куда обращаться работнику после увольнения, если работодатель уже успел ликвидироваться? С 13.08.2020 этот вопрос урегулирован. Законы № 210-Ф3 и № 203-Ф3 предусматривают упрощенный порядок увольнения сотрудника при ликвидации.

Так, чтобы не ждать, пока сотрудник проведет 2-3 месяца в попытках устроиться на работу, а потом придет за очередным пособием, его разрешено заменить единовременной компенсацией в размере 2-х среднемесячных заработков. То есть, за все потенциально оплачиваемые работодателем месяцы трудоустройства, включая третий, заплатить теперь можно сразу при увольнении работника.

Выплаченные уволенным сотрудникам в процессе ликвидации единовременные компенсации отменяют установленную ранее обязанность дожидаться, пока бывшие работники придут за пособиями, и позволяют продолжить процесс ликвидации. Причем сразу рассчитаться с работником можно не только в процессе новой ликвидации, но и в ходе текущей. При этом, если кому-то из уволенных работников уже были начислены пособия за второй месяц трудоустройства, они могут быть направлены в зачет единовременной выплаты.

\section{Зак^ючение}

Практика судебных разбирательств может оказать 
практическую помощь работодателю, или его штатному юристу, при возникновении спорных ситуаций в процессе ликвидации предприятия. К тому же, каждому сотруднику предприятия так же следует, надлежащим образом знакомиться с документами, которые предоставляются ему на подпись. Это не обязывает сотрудника в момент вручения приказа, уведомления его подписывать. Действующее законодательство предоставляет сроки для ознакомления, внесение поправок, в случае каких-либо недочетов. А в случае возникновения определенных вопросов задать их либо сотруднику отдела кадров, юристу, либо непосредственно руководителю. Таким образом, каждый сотрудник по своей воле или неволе зачастую сам делает себя жертвой сложившейся ситуации.

Законодательство РФ защищает права и гарантии сотрудников, таким образом, чтоб так же не были нарушены или оспорены права работодателей. Каждый рассматриваемый судом случай, носит уникальный характер. Ведь несмотря на то, что процесс ликвидации и уволь- нения на этом основании сотрудников строго закреплен в законе и является только легальным, работодатели могут умышленно либо по незнанию допустить разного рода ошибки и промахи.

Таким образом, если работодатель не принимал и не собирается принимать на законных основаниях решение о ликвидации предприятия, то проводить эту процедуру, как минимум, не корректно, неэффективно и в будущем очень затратно.

Увольняя работников в связи с ликвидацией предприятия (организации), необходимо произвести все стандартные выплаты при увольнении (например, выплатить зарплату). Средний месячный заработок за период трудоустройства и/или единовременная компенсация в любом случае должны быть выплачены до завершения ликвидации организации. В трудовом или коллективном договоре можно предусмотреть повышенный размер этих выплат.

\section{ЛИТЕРАТУРА}

1. Конституция Российской Федерации от 12 декабря 1993 г., с изменениями от 30 декабря 2008 г. (в последней редакции) // СПС Консультант Плюс (дата обращения 29.05.2020)

2. Короткова Е.А., Чиранова И.П. Понятие и виды гарантий при расторжении трудового договора по инициативе работодателя // https://cyberleninka.ru/ article/n/ponyatie-i-vidy-garantiy-pri-rastorzhenii-trudovogo-dogovora-po-initsiative-rabotodatelya (дата обращения 2.06.2020)

3. Путеводитель по кадровым вопросам. // http://www.consultant.ru/cons/cgi/online.cgi?req=doc\&base=PKV\&n=201\&dst=100653\#0649138497402219. (дата обращения 1.06.2020)

4. Трудовой кодекс Российской Федерации от 30.12.2001 N 197-Ф3 // СПС Консультант Плюс (дата обращения 3.06.2020)

5. Орловский Ю.П., Комментарий к Трудовому кодексу РФ 2019 год(постатейный) // https://kommentarii.org/2019/02/komment_tk. (дата 0бращения 1.06.2020)

6. Правила об очередных и дополнительных отпусках (утв. НКТ СССР 30.04.1930 N 169). Изданы на основании Постановления СНК СССР от 2 февраля 1930 г. протокол № 5/331, п. 28. // СПС Консультант Плюс (дата обращения 23.05.2020)

7. Никольский В.А. Трудовое право РФ. М.: Изд. центр ЕАОИ. 2016. - 404 с.

8. Закон Российской Федерации от 19.04.1991 N 1032-1 «0 занятости населения в Российской Федерации». // СПС Консультант Плюс (дата обращения 28.05.2020)

9. Гражданский кодекс Российской Федерации от 30.11.1994 № 51-Ф3 // СПС Консультант Плюс (дата обращения 27.05.2020)

10. Постановление Пленума Верховного Суда Российской Федерации от 2 июня 2015 г. № 21 г. Москва «0 некоторых вопросах, возникших у судов при применении законодательства, регулирующего труд руководителя организации и членов коллегиального исполнительного органа организации» // СПС Консультант Плюс (дата обращения 29.05.2020)

11. Кодекс Российской Федерации об административных правонарушениях от 30.12.2001 № 195-Ф3 // СПС Консультант Плюс (дата обращения 26.05.2020)

12. Постановление Пленума Верховного Суда РФ от 17.03 .2004 № 2 «0 применении судами Российской Федерации Трудового кодекса Российской Федерации». // СПС Консультант Плюс (дата обращения 26.05.2020)

13. Письмо Роструда от 08.06.2007 № 1921-6 «0 предоставлении ежегодных отпусков» // СПС Консультант Плюс (дата обращения 30.05.2020)

14. Письмо Федеральной службы по труду и занятости от 14 июня 2012 г. № 853-6-1 «0 предоставлении отпуска работнику при восстановлении на работе». // СПС Консультант Плюс (дата обращения 30.05.2020)

(c) Никитин Евгений Николаевич (nikitin@spbu.su).

Журнал «Современная наука: актуальные проблемы теории и практики» 